\title{
Pengolahan Limbah Domestik Kawasan Pesisir Dengan Subsurface Constructed Wetland Menggunakan Tanaman Jatropha curcas $L$.
}

\author{
Amalia Fildzah, Retno Suryani, Adistia Dian, Greace Fitriana, Arum Choirun Nisa, \\ Ganjar Samudro \\ Program Studi Teknik Lingkungan, Universitas Diponegoro, Jl. Prof Sudarto, Temabalang, Semarang \\ Email: amelf301@gmail.com
}

\begin{abstract}
Abstrak
Indonesia sebagai negara maritim seharusnya mampu memanfaatkan sumber daya maritimnya secara berkelanjutan. Namun, pemanfaatan sumber daya maritim selama ini cenderung mengabaikan kelestarian lingkungan. Akibatnya, perairan Indonesia banyak mengalami pencemaran yang salah satu sumber utamanya berasal dari limbah domestik pemukiman pesisir. Sementara itu, salah satu cara untuk mengolah limbah domestik adalah dengan sistem Subsurface Constructed Wetland. Sistem ini lebih dianjurkan karena mampu mengolah berbagai jenis limbah dengan efisiensi tinggi serta ekonomis dari segi biaya. Jarak Pagar adalah salah satu tanaman yang dapat dimanfaatkan sebagai fitoteknologi untuk meremediasi lingkungan tercemar. Selain itu, Jarak Pagar juga merupakan tanaman adaptif yang dapat tumbuh pada kondisi lingkungan beragam. Penelitian ini menggunakan 10 reaktor Subsurface Constructed Wetland dengan tanaman Jarak Pagar aliran continue yang terdiri atas 9 reaktor menggunakan variasi debit dan jarak penananaman serta 1 reaktor tanpa tanaman sebagai kontrol. Hasil penelitian menunjukkan bahwa sistem Subsurface Constructed Wetland dengan tanaman Jarak Pagar mampu menyisihkan COD sebesar 38-85\% dan TSS sebesar 75-91\%. Sementara itu, kinerja terbaik ditunjukkan oleh Reaktor 3 dengan debit $8 \mathrm{ml} /$ menit dan jarak penanaman $10 \mathrm{~cm}$ yang mencapai efisiensi penyisihan COD (84, 75\%) dan TSS (87,5\%). Dengan demikian, dapat disimpulkan bahwa sistem Subsurface Constructed Wetland dengan tanaman Jarak Pagar dapat menjadi salah satu solusi untuk mengelola lingkungan pesisir sehingga akan terwujud pembangunan maritim berkelanjutan.
\end{abstract}

Kata Kunci : Jatropha Curcas L., limbah domestik, pemukiman pesisir, Subsurface Constructed Wetland

\begin{abstract}
Indonesia as a maritime country should be able to exploit its maritime resources in a sustainable manner. However, the use of maritime resources have tended to pass of the environment. As a result, many Indonesian waters are run into pollutions that one major source comes from domestic wastes coastal settlements. Meanwhile, one way to treat domestic waste is using a system of Subsurface Constructed Wetland. This system is the most recommended because it is able to process different types of wastes with high efficiency and economical in terms of cost. Jatropha CurcasL is a plant that can be used as phytotechnology to remediate contaminated environments. In addition, Jatropha is also an adaptive plants that can grow on a variety of environmental conditions. This study uses 10 reactors of Subsurface Constructed Wetland with continuous flow of Jatropha plant which consist of nine reactors using flow variations and cultivation distances and 1 reactor without plants as a control. The results showed that the system of Subsurface Constructed Wetland with Jatropha plant capable removing 38-85\% of COD and 75-91\% of TSS. Meanwhile, the best result was shown by Reactor 3 with $8 \mathrm{ml} / \mathrm{mins}$ as the flow rate and $10 \mathrm{~cm}$ as the cultivation distance which reached the efficiency of COD removal (84, 75\%) and TSS (87.5\%). Thus, it can be concluded that the system of Subsurface Constructed Wetland with Jatropha curcas plant could be one solution to manage the coastal environment that will materialize sustainable maritime development.
\end{abstract}

Keywords : Jatropha Curcas L., domestic wastewater, coastal settlements, Subsurface Constructed Wetland 


\section{PENDAHULUAN}

Menurut Keputusan Menteri Lingkungan Hidup (Kepmen LH) nomor 112 Tahun 2013 tentang baku mutu air limbah domestik,air limbah domestik adalah air limbah yang berasal dari usaha dan atau kegiatan permukiman (real estate), rumah makan (restaurant), perkantoran, apartemen, dan asrama. Sementara itu, air limbah domestik merupakan penyebab terbesar pencemaran dan kerusakan pesisir di Indonesia. Kondisi demikian juga terjadi di pesisir utara Semarang. Akibat pencemaran limbah domestik, kualitas perairan di pesisir utara Semarang telah melampui baku mutu yang ditetapkan. Kondisi ini mengindikasikan adanya pencemaran lingkungan sehingga dapat berakibat negatif bagi kesehatan masyarakat sekitar.

Salah satu cara untuk mengolah limbah domestik adalah dengan sistem wetland. Sistem wetland adalah sistem yang termasuk pengolahan alami, dimana terjadi aktivitas pengolahan sedimentasi, filtrasi, transfer gas, adsorpsi, pengolahan kimiawi dan biologis karena aktivitas mikroorganisme dalam tanah dan aktivitas tanaman (Tchobanoglous, 1993). Menurut Tangahu \& Warmadewanthi (2001), sistem aliran bawah permukaan (Sub-Surface Flow Constructed Wetland) lebih dianjurkan dikarenakan sistem ini dapat mengolah berbagai jenis limbah dengan efisiensi pengolahan tinggi $(80 \%)$, serta ekonomis dari segi biaya. Pengolahan limbah domestik sistem Subsurface Constructed Wetland dengan menggunakan tanaman Cyperus Alternifolius L mampu menyisihkan COD 77,71 \%, BOD 98,88 \%, dan TSS 66,67 \% dalam waktu tinggal 5 hari (Supradata, 2005). Sementara itu, penelitian Prabowo dan Mangkoedihardjo (2013) tentang pengolahan air limbah katering dengan menggunakan tanaman Kana dalam Subsurface Constructed Wetland menghasilkan penurunan BOD dan COD yang optimum sebesar $75 \%$ dan $87 \%$.

Jarak Pagar adalah salah satu jenis tanaman semak yang tumbuh di daerah tropis. Tanaman yang dapat diperbanyak secara biji ataupun stek ini merupakan jenis tanaman adaptif yang dapat tumbuh dilingkungan dengan kondisi beragam. Selama ini Jarak Pagar dikenal sebagai sumber energi nabati karena bijinya yang banyak mengandung minyak. Sementara itu, menurut Mangkoediharjo dan Samudro (2010), Jarak Pagar adalah salah satu jenis tanaman yang dapat difungsikan sebagai fitoteknologi untuk meremediasi lingkungan yang tercemar dengan efisiensi tinggi. Karenanya, penggunaan Jarak Pagar sebagai fitoteknologi dalam sistem subsurface constructed wetland akan memberikan keuntungan ganda. Selain mampu menyisihkan polutan, sistem ini juga akan menjadi media pertumbuhan Jarak Pagar yang baik 
sehingga secara tidak langsung turut mendorong pengembangan energi alternatif di Indonesia.

\section{METODOLOGI PENELITIAN}

Penelitian ini menggunakan reaktor berupa kontainer ukuran $50 \mathrm{~cm}$ x $38 \mathrm{~cm}$ x $30 \mathrm{~cm}$ sebanyak 9 buah dengan sifat aliran kontinyu. Sembilan reaktor tersebut digunakan dengan variasi debit dan jarak penanaman. Variabel bebas yang digunakan adalah variasi debit dan jarak penanaman. Penelitian Risnawati dan Damanhuri (2009) tentang penyisihan logam pada lindi dalam Constructed Wetland menggunakan debit $12,5 \mathrm{ml} / \mathrm{menit}$. Oleh karenanya, dalam penelitian ini kami menggunakan variasi debit $8 \mathrm{ml} / \mathrm{menit}, 12 \mathrm{ml} / \mathrm{menit}$, dan $16 \mathrm{ml} / \mathrm{menit}$ dengan tujuan untuk mengetahui pengaruh debit. Penelitian Abdulgani, dkk (2013) menggunakan jarak penanaman Typha Angustifolia $15 \mathrm{~cm}$ dalam sistem subsurface flow constructed wetland. Penelitian Suswati dkk (2012) juga menggunakan jarak penanaman 15 $\mathrm{cm}$ dalam pengolahan limbah domestik menggunakan constructed wetland dengan tanaman Iris. Oleh karena itu, dalam penelitian ini menggunakan variasi jarak penanaman $10 \mathrm{~cm}, 15$ $\mathrm{cm}$, dan $20 \mathrm{~cm}$ untuk melihat pengaruh jarak. Variabel kontrol yang digunakan adalah ukuran tanaman jarak pagar dan ukuran reaktor. Sedangkan variabel terikatnya adalah konsentrasi COD dan TSS yang tersisih. Sementara itu, waktu pengambilan sampel dilakukan setelah proses berlangsung selama 15 jam.

Variasi debit serta jarak penanaman yang digunakan dalam penelitian ini dapat dilihat pada tabel sebagai berikut :

Tabel 1. Variasi Debit dan Jarak Penanaman

\begin{tabular}{ccc}
\hline Reaktor & Debit (ml/menit) & Jarak Penanaman $(\mathbf{c m})$ \\
\hline 1 & 8 & 10 \\
2 & 12 & 15 \\
3 & 16 & 20 \\
4 & 8 & 10 \\
5 & 12 & 15 \\
6 & 16 & 20 \\
7 & 8 & 10 \\
8 & 12 & 15 \\
9 & 16 & 20 \\
\hline
\end{tabular}




\section{HASIL DAN PEMBAHASAN}

\subsection{ANALISIS KARAKTERISTIK AWAL AIR LIMBAH}

Air limbah yang digunakan dalam penelitian ini adalah air limbah domestik kawasan pesisir utara Semarang. Hasil analisis karakteristik awal air limbah diperoleh konsentrasi COD (638 $\mathrm{mg} / \mathrm{l})$, TSS $(265 \mathrm{mg} / \mathrm{l}), \mathrm{pH}(6,68)$, dan suhu $\left(29^{\circ} \mathrm{C}\right)$. Karakteristik awal air limbah tersebut ditinjau dari parameter COD dan TSS telah melampaui baku mutu yang diatur dalam Peraturan Daerah Jawa Tengah Nomor 5 tahun 2012.

\subsection{TAHAP AKLIMATISASI}

Aklimatisasi tumbuhan adalah proses adaptasi suatu organisme dengan lingkungan sekitar sehingga tumbuhan dapat menyesuaikan diri dan dapat tumbuh dengan baik pada lingkungan yang baru (Prabowo dan Mangkoedihardjo, 2013). Aklimatisasi dalam penelitian ini dilakukan selama 3 hari, dengan dosis penambahan air bersih : air limbah secara bertahap yaitu hari pertama 100\%: 0\%, hari kedua 50\%: 50\%, dan hari ketiga 0\%: $100 \%$. Hasil pengamatan tumbuhan selama proses aklimatisasi dapat dilihat pada grafik sebagai berikut :

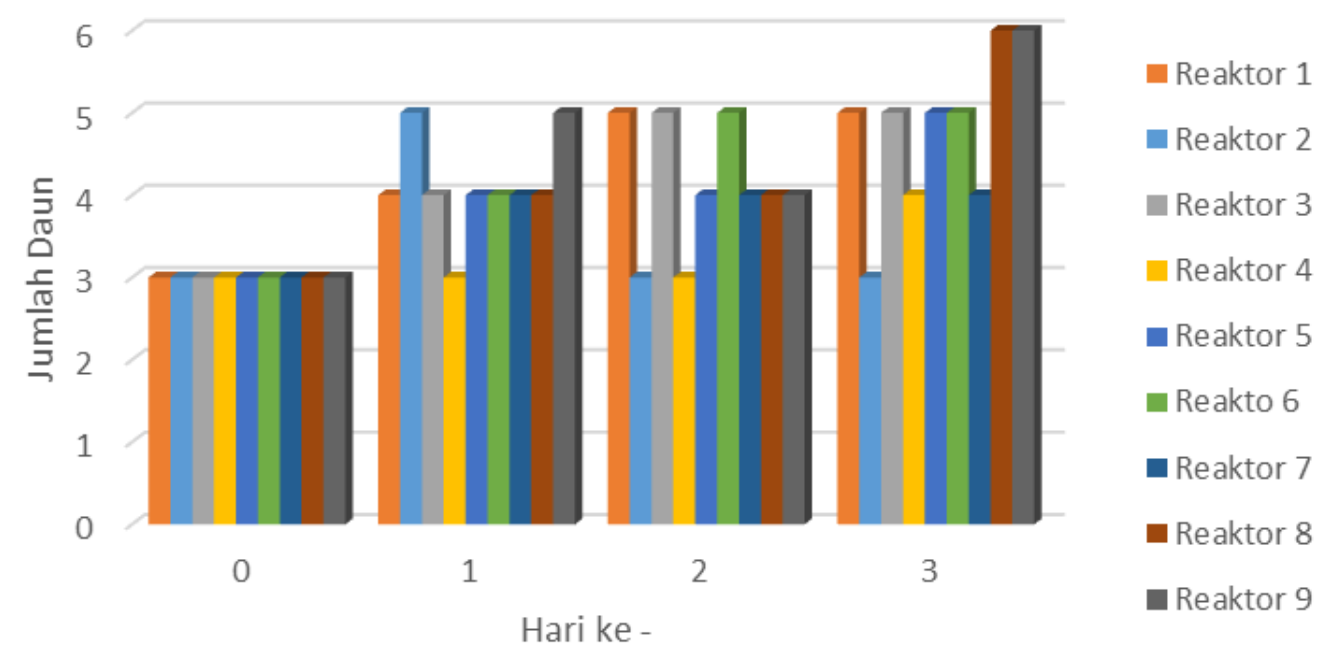

Gambar 1. Pertumbuhan Daun Rata-Rata

Berdasarkan grafik di atas, dapat diketahui apabila selama proses aklimatisasi cenderung terjadi pertambahan jumlah daun. Selain itu, tumbuhan juga terlihat tetap segar dan hijau. Hal ini menunjukkan bahwa Jarak Pagar mampu tumbuh dan beradaptasi dengan baik terhadap reaktor maupun air limbah yang harus diolah. 


\subsection{ANALISIS PENURUNAN COD}

Chemical Oxygen Demand (COD) adalah banyaknya oksigen dalam ppm atau miligram per liter yang dibutuhkan dalam kondisi khusus untuk menguraikan benda organik secara kimiawi (Sugiharto, 1987). Sementara itu, hasil analisis kualitas COD air limbah pada inlet dan outlet reaktor subsurface constructed wetland dapat dilihat pada tabel sebagai berikut:

Tabel 2. Efisiensi COD Tiap Reaktor

\begin{tabular}{cccc}
\hline Reaktor & $\begin{array}{c}\text { COD Inlet } \\
(\mathbf{m g} / \mathbf{l})\end{array}$ & $\begin{array}{c}\text { COD Outlet } \\
(\mathbf{m g} / \mathbf{l})\end{array}$ & $\begin{array}{c}\text { Efisiensi Pengolahan } \\
(\boldsymbol{\%})\end{array}$ \\
\hline 1 & 638 & 146,23 & 77,08 \\
2 & 638 & 123,61 & 80,63 \\
3 & 638 & 90,91 & 85,75 \\
4 & 638 & 310,51 & 51,33 \\
5 & 638 & 293,48 & 54,00 \\
6 & 638 & 272,23 & 57,33 \\
7 & 638 & 392,11 & 38,54 \\
8 & 638 & 380,79 & 40,32 \\
9 & 638 & 364,48 & 42,87 \\
\hline
\end{tabular}

Berdasarkan tabel di atas, dapat diketahui apabila sistem subsurface constructed wetland dengan tanaman Jarak Pagar dapat menyisihkan COD sebesar 38-85\%. Penyisihan COD tersebut terjadi karena dalam sistem subsurface constructed wetland terjadi mekanisme penyisihan secara biologis oleh mikroorganisme di sekitar perakaran tanaman di media reaktor. Dalam hal ini senyawa organik pada limbah dirombak oleh mikroorganisme menjadi senyawa-senyawa lain yang lebih sederhana. Senyawa-senyawa yang lebih sederhana tersebut selanjutnya dimanfaatkan sebagai nutrient oleh tanaman (Supradata, 2005). Pendapat serupa disampaikan Prabowo dan Mangkoedihardjo (2013) yang menyebutkan bahwa penurunan COD dalam sistem subsurface constructed wetland terjadi karena aktivitas mikroorganisme yang merubah COD menjadi nutrien untuk tumbuhan.

Sementara itu, apabila dibandingkan dengan baku mutu Peraturan Daerah Jawa Tengah Nomor 5 tahun 2012, kualitas COD outlet masing-masing reaktor adalah sebagai berikut : 
Tabel 3. Perbandingan COD Outlet dengan Baku Mutu

\begin{tabular}{cccc}
\hline Reaktor & $\begin{array}{c}\text { COD Outlet } \\
(\mathbf{m g} / \mathbf{l})\end{array}$ & $\begin{array}{c}\text { Baku Mutu } \\
(\mathbf{m g} / \mathbf{l})\end{array}$ & Keterangan \\
\hline 1 & 146,23 & 100 & Tidak Memenuhi \\
2 & 123,61 & 100 & Tidak Memenuhi \\
3 & 90,91 & 100 & Memenuhi \\
4 & 310,51 & 100 & Tidak Memenuhi \\
5 & 293,48 & 100 & Tidak Memenuhi \\
6 & 272,23 & 100 & Tidak Memenuhi \\
7 & 392,11 & 100 & Tidak Memenuhi \\
8 & 380,79 & 100 & Tidak Memenuhi \\
9 & 364,48 & 100 & Tidak Memenuhi
\end{tabular}

Berdasarkan tabel di atas, dapat diketahui apabila kinerja paling baik ditunjukkan oleh reaktor 3 dengan debit $8 \mathrm{ml} / \mathrm{menit}$ dan jumlah tanaman 9 batang sehingga memenuhi baku mutu yang ditetapkan. Sementara itu, untuk delapan reaktor lainnya, perlu waktu tinggal yang lebih lama agar bisa menghasilkan kualitas outlet yang memenuhi baku mutu. Efisiensi penyisihan COD dari sistem subsurface constructed wetland dengan tanaman Jarak Pagar ini lebih baik apabila dibandingkan dengan menggunakan beberapa tanaman lainnya. Dengan waktu tinggal 1 hari, diperoleh efisiensi penyisihan COD $72 \%$ untuk subsurface constructed wetland dengan tanaman Cattail maupun Kana (Dhokikah, Y 2006). Penelitian Prabowo dan Mangkoedihardjo (2013) tentang pengolahan air limbah katering dengan menggunakan tanaman Kana dalam Subsurface Constructed Wetland menghasilkan penurunan BOD dan COD yang optimum sebesar $75 \%$ dan $87 \%$. Sementara itu, penelitian Siswanto (2014) tentang pengolahan limbah hotel menggunakan Constructed wetland dengan media tanah gambut dan tanaman bambu air menghasilkan penyisihan COD dengan efisiensi tertinggi $55,98 \%$ dengan waktu tinggal 4 hari.

\subsection{ANALISIS PENURUNAN TSS}

Total Suspended Solid (TSS) adalah jumlah berat dalam mg/l kering Lumpur yang ada didalam air limbah setelah mengalami penyaringan dengan membran berukuran 0,45 mikron (Sugiharto, 1987). Sementara itu, hasil analisis kualitas TSS air limbah pada inlet dan outlet reaktor subsurface constructed wetland dapat dilihat pada tabel sebagai berikut : 
Tabel 4. Efisiensi TSS Tiap Reaktor

\begin{tabular}{cccc}
\hline Reaktor & $\begin{array}{c}\text { TSS Inlet } \\
(\mathbf{m g} / \mathbf{l})\end{array}$ & $\begin{array}{c}\text { TSS Outlet } \\
(\mathbf{m g} / \mathbf{l})\end{array}$ & $\begin{array}{c}\text { Efisiensi Pengolahan } \\
(\boldsymbol{\%})\end{array}$ \\
\hline 1 & 265 & 22 & 92 \\
2 & 265 & 27,5 & 90 \\
3 & 265 & 33 & 88 \\
4 & 265 & 33 & 88 \\
5 & 265 & 41,25 & 84 \\
6 & 265 & 49,5 & 81 \\
7 & 265 & 44 & 83 \\
8 & 265 & 55 & 79 \\
9 & 265 & 66 & 75 \\
\hline
\end{tabular}

Berdasarkan tabel di atas, dapat diketahui apabila sistem subsurface constructed wetland dengan tanaman Jarak Pagar dapat menyisihkan TSS sebesar 75-91\%. Penurunan TSS ini terjadi karena dalam sistem subsurface constructed wetland juga berlangsung proses filtrasi serta sedimentasi yang banyak dipengaruhi oleh porositas media (Supradata, 2005).

Sementara itu, apabila dibandingkan dengan baku mutu Peraturan Daerah Jawa Tengah Nomor 5 tahun 2012, kualitas TSS outlet masing-masing reaktor adalah sebagai berikut :

Tabel 5. Perbandingan TSS Outlet dengan Baku Mutu

\begin{tabular}{cccc}
\hline Reaktor & $\begin{array}{c}\text { TSS Outlet } \\
(\mathbf{m g} / \mathbf{l})\end{array}$ & $\begin{array}{c}\text { Baku Mutu } \\
(\mathbf{m g} / \mathbf{l})\end{array}$ & Keterangan \\
\hline 1 & 22 & 100 & Memenuhi \\
2 & 27,5 & 100 & Memenuhi \\
3 & 33 & 100 & Memenuhi \\
4 & 33 & 100 & Memenuhi \\
5 & 41,25 & 100 & Memenuhi \\
6 & 49,5 & 100 & Memenuhi \\
7 & 44 & 100 & Memenuhi \\
8 & 55 & 100 & Memenuhi \\
9 & 66 & 100 & Memenuhi \\
\hline
\end{tabular}

Berdasarkan tabel di atas, dapat diketahui apabila kualitas outlet TSS dari semua reaktor telah memenuhi baku mutu yang ditetapkan. Hal ini dibuktikan dengan air di outlet yang tampak 
jernih dibandingkan dengan kualitas air di inlet. Efisiensi penyisihan TSS dalam sistem subsurface constructed wetland dengan tanaman Jarak Pagar ini lebih tinggi dibanding menggunakan tanaman lainnya. Dengan waktu tinggal 1 hari diperoleh efisiensi penyisihan TSS $41 \%$ untuk subsurface constructed wetland dengan tanaman Cattail dan $46 \%$ untuk tanaman Kana (Dhokikah, Y 2006). Sementara itu, penelitian Siswanto (2014) tentang pengolahan limbah hotel menggunakan Constructed wetland dengan media tanah gambut dan tanaman bambu air menghasilkan penyisihanTSS dengan efisiensi tertinggi $85,26 \%$ dengan waktu tinggal 4 hari.

\section{KESIMPULAN}

Sistem Subsurface Constructed Wetland dengan tanaman Jarak Pagar mampu menyisihkan COD sebesar 38-85\% dan TSS sebesar 75-91\%. Sementara itu, kinerja terbaik ditunjukkan oleh Reaktor 3 dengan debit $8 \mathrm{ml} / \mathrm{menit}$ dan jarak penanaman $10 \mathrm{~cm}$ yang mencapai efisiensi penyisihan COD $(\mathbf{8 4}, \mathbf{7 5} \%)$ dan TSS $(\mathbf{8 7 , 5 \%})$. Dengan demikian, dapat disimpulkan bahwa secara keseluruhansistem Subsurface Constructed Wetland dengan tanaman Jarak Pagar dapat digunakan sebagai upaya pengolahan limbah domestik di kawasan pesisir.

\section{UCAPAN TERIMA KASIH}

Terima kasih kepada Dirjen Belmawa Kemenristekdikti yang telah memberikan pendanaan bagi penelitian ini melalui Program Kreativitas Mahasiswa (PKM) bidang penelitian tahun 2015-2016.

\section{DAFTAR PUSTAKA}

Abdulgani, Hamdani, Munifatul I., Sudarno, (2013), Kemampuan Tumbuhan Typha Angustifolia Dalam Sistem Subsurface Flow Constructed Wetland Untuk Pengolahan Limbah Cair Industri Kerupuk (Studi Kasus Limbah Cair Sentra Industri Kerupuk Desa Kenanga Kecamatan Sindang Kabupaten Indramayu Jawa Barat). Prosiding Seminar Nasional Pengelolaan Sumberdaya Alam dan Lingkungan.

Dhokikah, Y. (2006), Pengolahan Air Bekas Domestik Dengan Sistem Constructed Wetland Aliran Subsurface Untuk Menurunkan COD, TS dan Deterjein. Tesis. Institut Teknologi Sepuluh November Surabaya.

Mangkoediharjo, S. dan Samudro, G., (2010), Fitoteknologi Terapan. Graha Ilmu: Yogyakarta. 
Prabowo, Aninditas Laksmi dan Mangkoedihardjo S. (2013), Penurunan BOD dan COD pada Air Limbah Katering Menggunakan Konstruksi Wetland Subsurface Flow dengan Tumbuhan Kana (Canna indica). Paper Teknik Lingkungan. Institut Teknologi Sepuluh November Surabaya.

Risnawati, I. dan Damanhuri, T. P. (2009), Penyisihan Logam Pada Lindi Menggunakan Constructed Wetland. Jurnal Teknik Lingkungan. Institut Teknologi Bandung.

Siswanto., Darmayanti L., Handayani Y., L.., dan Ridwan R., (2014), Pengolahan Air Limbah Hotel Dengan Metode Free Surface Constructed Wetland Menggunakan Tumbuhan Equisetum hymale. Jurnal Teknobiologi, V(1) 2014: 37 - 42 ISSN : 2087 $-5428$

Sugiharto (1987), Dasar-Dasar Pengelolaan Air Limbah. Jakarta : UI PRESS.

Supradata (2005), Pengolahan Limbah Domestik Menggunakan Tanaman Hias Dalam Sistim Lahan Basah Buatan Aliran Bawah Permukaan. Tesis Pascasarjana Universitas Diponegoro Semarang.

Suswati, Purna A. C. S., Wibisono G., MasrevaniahA., Arfiati D., (2012), Analisis Luasan Constructed Wetland Menggunakan Tanaman Iris dalam Mangolah Air Limbah Domestik (Greywater). Indonesian Green Technology Journal.Vol. 1 No. 3, 2012

Tangahu, B. V., and I. D. A. A. Warmadewanthi. (2001), Pengelolaan Limbah Rumah Tangga dengan Memanfaatkan Tanaman Cattail (Typha Angustifolia) dalam Sistem Constructed Wetland. Surabaya : Institut Teknologi Sepuluh November.

Tchobanoglous, G., Burton, F. L., \& Stensel, H. D. (1993), Wastewater Engineering: Treatment and Reuse Fourth Edition. China : McGraw-Hill. 